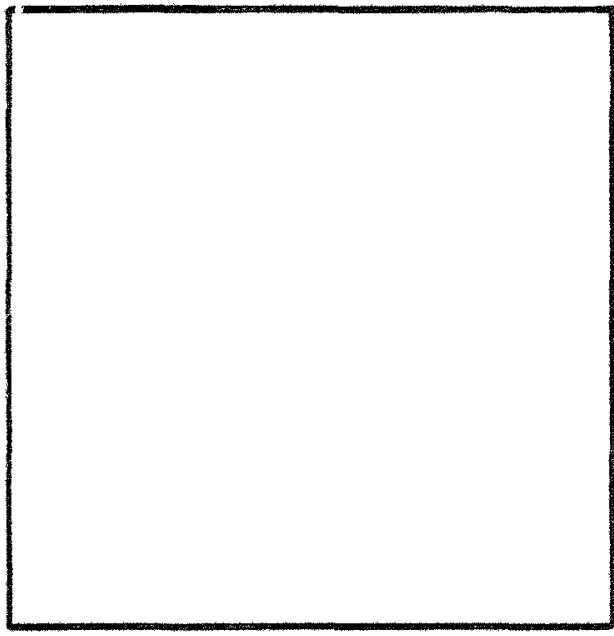

BDX-613-2848

\title{
Synthesis and Characterization of Diallyl Phthalate Prepolymers
}

By G. K. Baker and B. G. Parker

Published December 1982

Final Report

G. K. Baker, Project Leader

DO NOT MICROFILM Cand COVER

. . . . s. $30-m$ $-$

Prepared for the United States Department of Energy Under Contract Number DE-ACO4-76-DP00613. 
This report was prepared as an account of work sponsored by the United States Government. Neither the United States nor the United States Department of Energy, nor any of their employees, nor any of their contractors, subcontractors, or their employees, makes any warranty, express or implied, or assumes any legal liability or responsibility for the accuracy, completeness or usefulness of any information, apparatus, product or process disclosed, or represents that its use would not infringe privately owned rights.

Printed in the United States of America

Available From the National Technical Information Service, U.S. Department of Commerce, 5285 Port Royal Road, Springfield, Virginia 22161.

Price: Microfiche $\$ 3.00$

Paper Copy $\$ 4.50$ 


\section{DISCLAIMER}

This report was prepared as an account of work sponsored by an agency of the United States Government. Neither the United States Government nor any agency Thereof, nor any of their employees, makes any warranty, express or implied, or assumes any legal liability or responsibility for the accuracy, completeness, or usefulness of any information, apparatus, product, or process disclosed, or represents that its use would not infringe privately owned rights. Reference herein to any specific commercial product, process, or service by trade name, trademark, manufacturer, or otherwise does not necessarily constitute or imply its endorsement, recommendation, or favoring by the United States Government or any agency thereof. The views and opinions of authors expressed herein do not necessarily state or reflect those of the United States Government or any agency thereof. 


\section{DISCLAIMER}

Portions of this document may be illegible in electronic image products. Images are produced from the best available original document. 


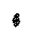

$B D X-613-2848$

Distribution Category UC-25

$B D X-613-2848$

DE83 004945

SYNTHESIS AND CHARACTERIZATION OF DIALLYL PHTHALATE PREPOLYMERS

By G. K. Baker

and B. G. Parker

Published December 1982

Final Report

G. K. Baker, Project Leader

Project Team:

G. W. Griffith

L. E. Lacy

C. I. Long

R. E. Smith

R. A. Whitaker

Technical Communications

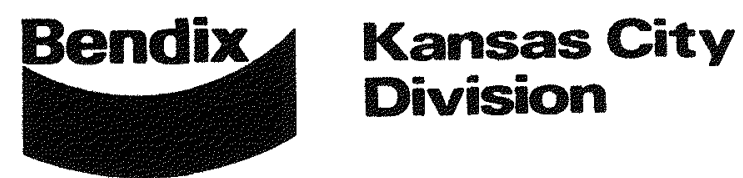


BDX-613-2848, Final Report, Published December 1982

Prepared by G. K. Baker and B. G. Parker

Methods for the laboratory synthesis of diallyl phthalate prepolymers were evaluated. The chemical, physical, and molecular weight properties of several prepolymers synthesized were also evaluated and compared to those properties exhibited by Dapon 35 and Daiso 35, manufactured by FMC Corporation and osaka-soda, respectively. Glass-filled molding compounds from four of the prepolymers having molecular weight distributions ranging from 1.9 to 40.2 were prepared and tested at the Monsanto Research Corporation, Mound Facility. The processing characteristics and physical and electrical properties of two molding compounds were found to be comparable to similar compounds made from Dapon 35 and Daiso 35.

RGS/jas

DTR13/a

This report was prepared as an account of work sponsored by the United States Government. Neither the United States, nor the United States Department of Energy, nor any of their employees. nor any of their contractors, subcontractors, or their employees. makes any warranty, expressed or implied or assumes any legal liability or responsibility for the accuracy, completeness or usefulness of any information, apparatus, product, or process disclosed, or represents that its use would not infringe privately owned rights.
The Bendix Corporation Kansas City Division P. O. Box 1159 Kansas City, Missouri 64141 
Diallyl Phthalate Prepolymer Solution Viscosity Versus Refractive Index at $25^{\circ} \mathrm{C}$ (RO2128-01). . . . . . . . . . . .

2

Gel Permeation Chromatographs of Diallyl Phthalate Prepolymers (RO2128-02). . . .

TABLES

Number

Page

1.

Summary of the Characterization of Two Commercial and Four Bendix-Synthesized Diallyl Phthalate Prepolymers. . . . . . . . .

Processability of DAP Prepolymers in DAP Fiberglass Molding Compounds . . . . . .

Analysis and Methods Used in the Mound Characterization of DAP Molding Compounds. . . . . . . . . . . . . . .

Mound Chemical Analysis of Diallyl Phthalate Fiberglass Molding Compounds . . . . . .

Properties of DAP Prepolymers in Shortglass DAP Molding Compounds. . . . . . . . . 


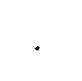




\section{SUMMARY}

Because there is no longer a domestic source for DAP prepolymers used in molding compounds at Bendix Kansas City, methods for the laboratory synthesis of such prepolymers have been evaluated.

Synthesis methods involving the free radical vinyl polymerization of DAP monomer using hydrogen peroxide or di-benzoyl peroxide yielded prepolymers with similar chemical, physical, and molecular weight properties as Dapon 35 and a Japanese prepolymer, Osaka-Soda's Daiso 35.

Fiberglass-filled molding compounds made from four Bendix prepolymers were prepared and evaluated at Monsanto Research Corporation, Mound Facility. The four prepolymers represented the widest possible types of prepolymers prepared in this endeavor; the molecular weight distributions ranged from 1.9 to 40.2 .

The processing characteristics of two of the prepolymers during preparation of the molding compounds were graded excellent and similar to compounds made from Dapon 35 and Daiso 35 . These two prepolymers had molecular weight distributions similar to Dapon 35. One of these two molding compounds met all the acceptance criteria. The other failed one test, arc resistance, which at the time was suspected of error. A retest could not be performed because of a lack of more molding compounds.

The manufacture of acceptable DAP prepolymers in the Bendix Chemical Polymer Facility for use at Mound and at Bendix, if necessary, appears to be feasible. 
DISCUSSION

\section{SCOPE AND PURPOSE}

The objective of this project was to develop methods for the laboratory synthesis of diallyl phthalate (DAP) prepolymers suitable for use in the formulation of DAP molding compounds. A specific objective was to synthesize a replicate of Dapon 35 which is no longer commercially available in the United states.

\section{ACTIVITY}

General Reactions and Structures

Ortho-diallyl phthalate has the chemical structure<smiles>C=CCOC(=O)c1ccccc1C(=O)OCC=C</smiles>

It is converted to prepolymer by a vinyl polymerization mechanism using a peroxide initiator whose ideal repeating unit is:

$$
\left[\mathrm{CH}_{2}-\underset{\mathrm{R}}{\mathrm{CH}}\right]_{\mathrm{n}}
$$


where $R$ is

$$
-\mathrm{CH}_{2}-\mathrm{O}-\underset{\mathrm{O}}{-\mathrm{C}} \longrightarrow \underset{\mathrm{O}}{\mathrm{C}}-\mathrm{C}-\mathrm{O}-\mathrm{CH}_{2}-\mathrm{CH}=\mathrm{CH}_{2}
$$

In such an ideal case, each repeating unit contains one ally 1 group $\left(-\mathrm{CH}_{2}-\mathrm{CH}=\mathrm{CH}_{2}\right)$. During the formation of the prepolymer, however, cyclic structures can form along the backbone involving loss of some of the allyl groups. The most likely cyclic structure to form is the following 11 -membered ring.<smiles>CCC1COC(=O)c2ccccc2C(=O)OCC(CC(C)(C)C)C1</smiles>

Because the monomer is difunctional and the prepolymer has pendant, active allyl groups, the polymerization of diallyl phthalate can be carried out only to about 25 percent conversion of monomer before crosslinking and gellation occur.

Synthesis Methods Evaluated

Most of the synthesis effort has been based on information from a patent assigned to the FMC Corporation. ${ }^{1}$ The patent describes 
the synthesis of DAP prepolymer whose polymerization catalyst is hydrogen peroxide $\left(\mathrm{H}_{2} \mathrm{O}_{2}\right)$ or a combination of $\mathrm{H}_{2} \mathrm{O}_{2}$ and an organic peroxide such as di-benzoyl peroxide.

One procedure employing $\mathrm{H}_{2} \mathrm{O}_{2}$ as the peroxide initiator involves stirring and heating $400 \mathrm{~g}$ ortho-diallyl phthalate, $42 \mathrm{~g}$ isopropyl alcohol, and $4.8 \mathrm{~g} 50$ percent $\mathrm{H}_{2} \mathrm{O}_{2}$ to reflux temperature (about $106^{\circ} \mathrm{C}$ ) for 8 to $10 \mathrm{~h}$. The product, a white solid, is recovered by slowly adding the reaction mixture into rapidly stirred methyl alcohol. The recovery of product is the most difficult and time-consuming step in the process. Although the final product is a white powder, the initial precipitation of product in methyl alcohol can result in a white viscous liquid. This is caused by the solubility of DAP polymer in DAP monomer. Only about 25 to 30 percent of DAP monomer is converted to prepolymer. Even though DAP prepolymer is insoluble in methyl alcohol, there is sufficient monomer in the initial precipitation media for the DAP prepolymer to partially solvate the prepolymer and form a white viscous liquid as a separate phase from the methyl alcohol. Very slow addition to the methyl alcohol and repetitive washings in fresh methyl alcohol are required to obtain a powder. Finally, the powder is dried at room temperature under a vacuum. Heating the DAP prepolymer only a little above room temperature causes the material to coalesce and form a hard cake.

A second procedure was evaluated in which an organic peroxide was the free radical initiator and a chain transfer agent, carbon tetrachloride, was used. The procedure involves the stirring and heating of $400 \mathrm{~g}$ ortho-diallyl phthalate, $8 \mathrm{~g}$ carbon tetrachloride, $8 \mathrm{~g}$ methanol, and $1.6 \mathrm{~g}$ di-benzoyl peroxide to reflux temperature (about $106^{\circ} \mathrm{C}$ ) for 2 to $3 \mathrm{~h}$. The product is recovered as described in the first method.

A third method evaluated involves the thermal polymerization of DAP monomer. 2 Air zero is slowly bubbled into $400 \mathrm{~g}$ of orthodiallyl phthalate and stirred and heated to $220^{\circ} \mathrm{C}$ for 2 to 4

hours. The product is recovered as described previously.

In-Process Analysis

Because the reaction products will gel if the reaction is carried beyond about 25 percent conversion of monomer, a quick in-process test method to determine the extent of reaction was needed. Measurement of both viscosity and refractive index was made on most of the DAP prepolymer runs attempted. 
Determination of viscosity as an in-process analysis is the most definitive and reproducible method, but required too much time in some of the faster reactions. The method involved removing 10 to $15 \mathrm{~g}$ reaction product, cooling it to $25^{\circ} \mathrm{C}$, and measuring the viscosity in a Cannon ubbelohde viscometer. The entire process requires about $20 \mathrm{~min}$. In some of the faster reactions, the viscosity of the material in the reaction vessel may increase greatly during that time period. In several instances, gellation occurred.

Measurement of refractive index requires only 2 to $3 \mathrm{~min}$, but does not have the accuracy or reproducibility of the viscosity method. Differences in color of the monomer and prepolymer reaction mixture probably attribute to the problems with the refractive index measurement. However, the refractive index method appears to be an acceptable method for the in-process analysis of DAP prepolymers desired for use in making molding compounds. A plot of viscosity versus refractive index from the in-process analysis of various reaction runs is illustrated in Figure 1. A general linear relationship is observed. The desired viscosity range for acceptable prepolymer is fairly broad, 0.25 to $0.95 \mathrm{~Pa} \cdot \mathrm{s}$ as a 25 percent solution of DAP prepolymer in DAP monomer. This corresponds to a refractive index range of about 1.529 to 1.532 (Figure 1). Such a range is easily monitored by refractive index even with the problems associated with the method.

\section{Analytical Characterization of DAP Prepolymers}

The molecular weight properties of the prepolymers were determined using a Model 200 Waters Gel Permeation Chromatograph. The samples tested were 0.5 percent solutions of prepolymer in tetrahydrofuran. Four columns of Micro-styragel having porosity ratings of $10^{6}, 10^{5}, 10^{4}$ and $10^{3} \AA$ were used; the detector was a differential refractometer.

The elution of residual monomer in the prepolymer was well separated from that of the prepolymer, allowing a quantitative analysis for residual monomer based on the peak height of the monomer.

Gel permeation chromatographic (GPC) analysis was also made for general comparison of molecular weight distribution by a different instrument. The instrument used was a Model ALC-201 Waters Liquid Chromatograph, with a differential refractometer detector. 


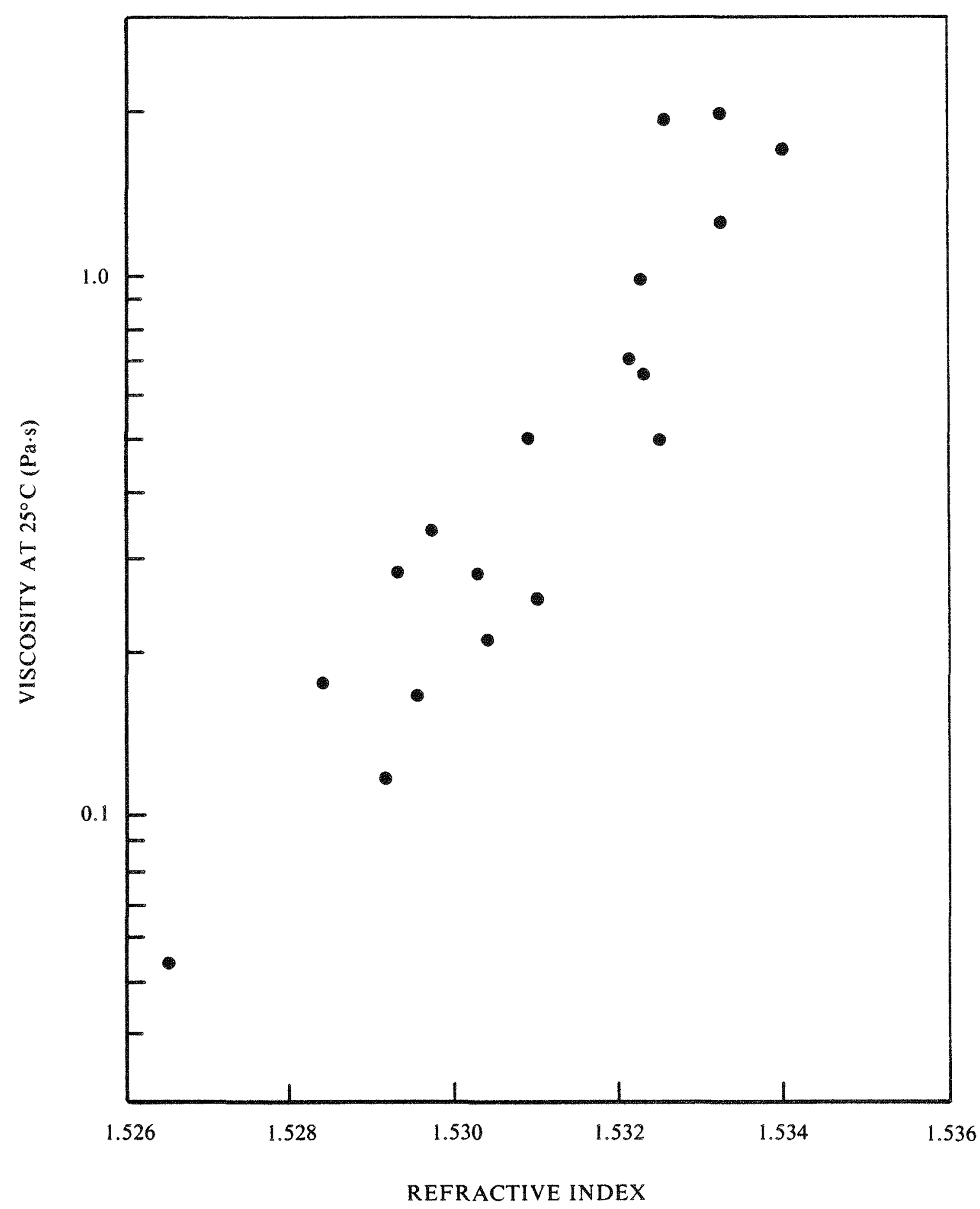

Figure 1. Diallyl Phthalate Prepolymer Solution Viscosity Versus Refractive Index at $25^{\circ} \mathrm{C}$ 
This instrument had two Micro-spherogel columns with porosities of $10^{4}$ and $10^{3} \AA$. The solutions analyzed were 1 percent prepolymer in tetrahydrofuran. The pump setting was 35 and the chart paper speed was $0.5 \mathrm{~cm} / \mathrm{min}$.

A method for determining the allyl content in DAP prepolymers using a Nicolet Model 7199 Fourier Transform Infrared Spectrophotometer (FTIR) was developed. Calibration curves were prepared using pure DAP monomer at concentrations ranging from 1 to $10 \mathrm{~g} / \mathrm{I}$ in methylene chloride and ran in $0.5 \mathrm{~mm}$ cells at a gain of 2. The methylene chloride spectrum was subtracted from the solution spectra using the absorbance band at $1552 \mathrm{~cm}^{-1}$. Using a reference spectra of dibutyl phthalate, the carbonyl band was subtracted at $1725 \mathrm{~cm}^{-1}$. The peak height was then calculated at $1650 \mathrm{~cm}^{-1}$ using a baseline from 1666 to $1625 \mathrm{~cm}^{-1}$. The pendant allyl content, or allyl groups on the prepolymer backbone, can then be calculated by subtracting the allyl content due to residual monomer (determined by GPC from the total ally found by FTIR).

Results and Discussion of Bendix Characterization of DAP Prepolymers

Forty-one batches of DAP prepolymer were synthesized to evaluate the various synthesis methods, effect of peroxide catalyst (type and concentration), reaction time, control of molecular weight, reproducibility, and yield. Four of the larger batches were sent to Mound for evaluation of DAP molding compounds made from Bendix-synthesized prepolymers (DAPP).

Table 1 summarizes the Bendix characterization results of these four batches (DAPP 11, 14/15, 39, and 40), Dapon 35 (Lot QC23797), and Daiso 35 (Sample 1). DAPP 14/15 is a mixture of two batches of prepolymer which had very similar properties. Data from the four Bendix prepolymers (Table 1) represent the extreme range of most of the batches synthesized. The batches that gelled and the batch prepared by thermal polymerization were not analyzed. Because of the yellow color of the latter, the material was not considered to be representative of the type of prepolymer desired by Mound.

As observed from the reaction time, the rate of polymerization of DAP monomer is about twice as fast using di-benzoyl peroxide compared to hydrogen peroxide. With the exception of DAPP 14/15, the yields were about the same. In addition, the reproducibility 
Table 1. Summary of the Characterization of Two Commercial and Four Bendix-Synthesized Diallyl Phthalate Prepolymers

\begin{tabular}{|c|c|c|c|c|c|c|}
\hline Condition & Dapon 35 & Daiso 35 & DAPP 11 & DAPP $14 / 15$ & DAPP 39 & DAPP 40 \\
\hline \multicolumn{7}{|l|}{$\begin{array}{l}\text { Peroxide Ini- } \\
\text { tiator }\end{array}$} \\
\hline (Percent) & & & $1.4 *$ & $1.4 *$ & $0.5 * *$ & $0.5 * *$ \\
\hline \multicolumn{7}{|l|}{ Reaction } \\
\hline Time (h) & & & 9.0 & 9.0 & 4.5 & 3.5 \\
\hline \multicolumn{7}{|l|}{ Prepolymer } \\
\hline \multicolumn{7}{|l|}{ Yield } \\
\hline (Percent) & & & 24.6 & 12.5 & 23.3 & 27.0 \\
\hline \multicolumn{7}{|l|}{ Viscosity at } \\
\hline $25^{\circ} \mathrm{C}(\mathrm{Pa} \cdot \mathrm{s}) \dagger$ & 0.325 & 0.265 & 0.295 & 0.1 & 4.415 & 0.966 \\
\hline \multicolumn{7}{|l|}{ Residual } \\
\hline \multicolumn{7}{|l|}{ Monomer } \\
\hline (Percent) & 1.2 & 5.6 & 1.7 & 7.1 & 4.4 & 5.8 \\
\hline \multicolumn{7}{|l|}{ Total Ally1 } \\
\hline (Percent) & 9.2 & 9.6 & 9.7 & 10.3 & 9.6 & 10.1 \\
\hline \multicolumn{7}{|l|}{ Pendent Allyl } \\
\hline (Percent) $+t$ & 8.8 & 7.7 & 9.1 & 8.0 & 8.5 & 8.2 \\
\hline \multicolumn{7}{|l|}{ Molecular } \\
\hline \multicolumn{7}{|l|}{ Weight } \\
\hline \multicolumn{7}{|l|}{ Number } \\
\hline Average & 9,500 & 11,500 & 10,200 & 6,300 & 14,000 & 12,800 \\
\hline \multicolumn{7}{|l|}{ Weight } \\
\hline \multicolumn{7}{|c|}{$\begin{array}{l}\text { Average } 67,000 \\
\text { Distribu- }\end{array}$} \\
\hline $\begin{array}{l}\text { Distribu- } \\
\text { tion }\end{array}$ & 7.0 & 4.3 & 3.9 & 1.9 & 40.2 & 10.6 \\
\hline $\begin{array}{r}* 50 \text { Percent hy } \\
* * \text { Di-benzoy } 1 \text { pe } \\
+25 \text { Percent so } \\
++ \text { Total ally } 1\end{array}$ & $\begin{array}{l}\text { ydrogen pe } \\
\text { eroxide. } \\
\text { olution in } \\
\text { content les }\end{array}$ & nomer. & & & & \\
\hline
\end{tabular}


of reaction rate using hydrogen peroxide was less than desired. The reason for this is not known and represents an item for further study.

The low yield with DAPP $14 / 15$ was caused by the deliberate premature termination of the reaction to obtain a sample representative of a low molecular weight prepolymer for evaluation at Mound.

The residual monomer in the prepolymers varied from 1.2 to 7.1 percent. As discussed earlier, this is primarily a function of the recovery process. The more washings, the less monomer will be entrapped in the prepolymer.

The manufacture of DAP parts involves the molding of a compound consisting of DAP prepolymer, fillers, processing aid, inhibitor, and a peroxide catalyst. During molding, the pendant allyl groups of the prepolymer and residual monomer are further polymerized to form crosslinks. Knowledge of the number of allyl. groups available for crosslinking during molding is important. The pendant allyl contents of the prepolymers listed in Table 1 vary from 7.7 to 9.1 percent. The Osaka-Soda prepolymer had the lowest pendant allyl content ( 7.7 percent); DAPP 11 had the highest (9.1 percent). The reaction conditions which control the amount of pendant allyl groups obtained in DAP prepolymers are not known at this time. No pattern is observed from the DAPP batches made to date. The range of 7.7 to 9.1 percent pendant allyl may represent the normal statistical distribution obtained in the preparation of such prepolymers.

The molecular weight properties of the prepolymers are very interesting, especially the molecular weight distributions (MWD). The MWD for all the prepolymers given in Table 1, with the exception of DAPP 14/15, are broad compared to most polymers synthesized by a vinyl addition polymerization mechanism.

Examination of the GPC curves in Figure 2 clearly show the reason for the large values of MWD. Dapon 35, Daiso 35, DAPP 11, and DAPP 40 have distinct bimodal molecular weight distributions and DAPP 39 has a distinct trimodal distribution. Actually, Dapon 35 and DAPP 40 have a trace of trimodal character (as seen by the shoulder at about 22 min elution time). An estimated number average molecular weight for DAP prepolymer eluting at 34 to 36 min is about 8000 , and material eluting at 26 to $28 \mathrm{~min}$ is approximately 60,000 . The third peak in the GPC curve of DAPP-39 


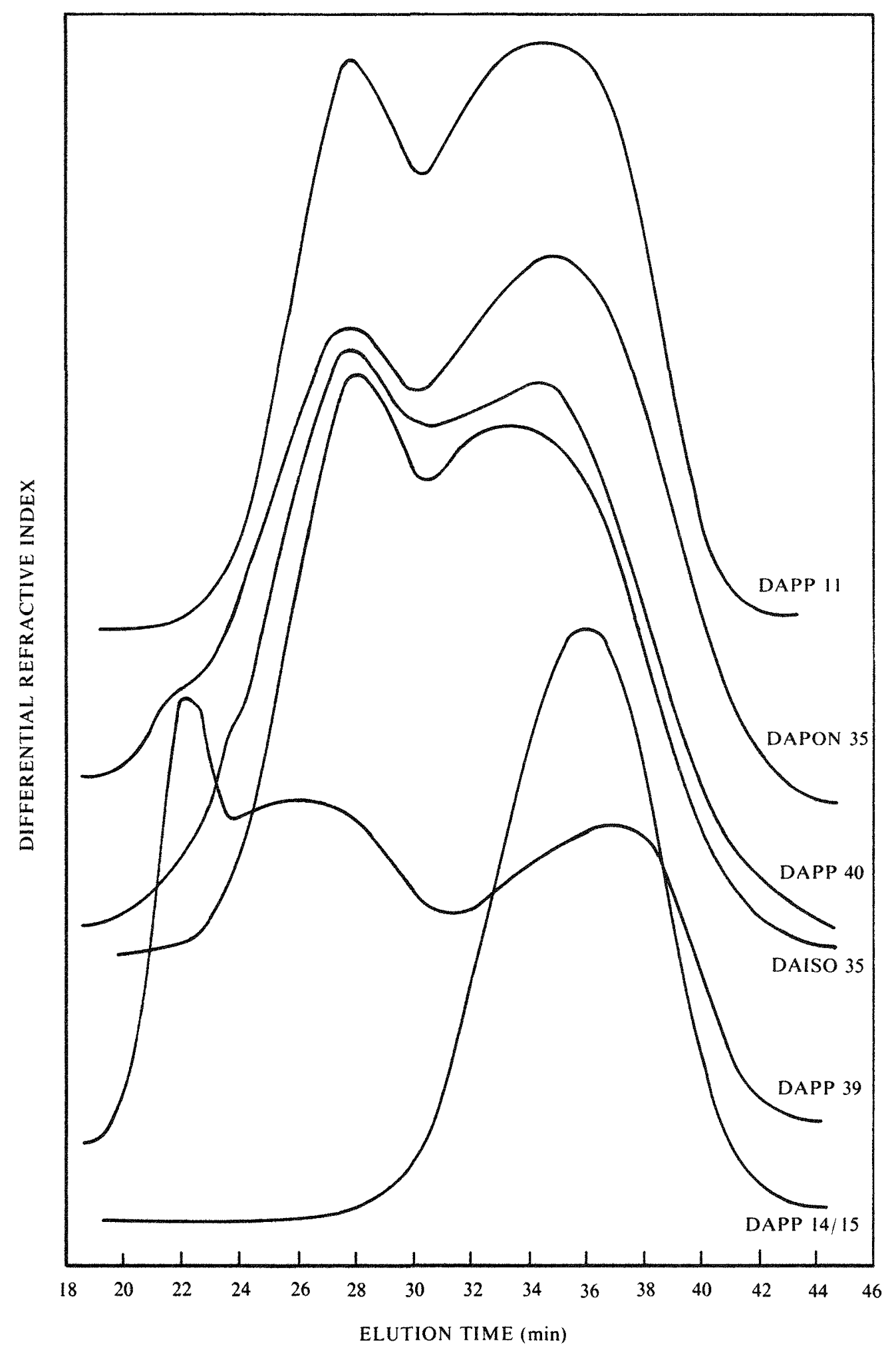

Figure 2. Gel Permeation Chromatographs of Diallyl Phthalate Prepolymers 
eluting at $22 \mathrm{~min}$ represents only a portion of the true peak. The molecular size exclusion limit of the GPC column set used in this analysis is such that the entire MWD of the third peak could not be resolved. Consequently, the number average molecular weight of the third peak in DAPP 39 cannot be calculated.

The GPC curves in Figure 2 were obtained using the Model ALC-201 Waters Liquid Chromatograph. This method has the effect of narrowing the $\mathrm{X}$-axis (molecular weight). These curves, however, are more illustrative of the multimodality of the prepolymers compared to the GPC curves obtained by the Model 200 Waters Chromatograph.

A reasonable explanation for the multimodality of DAP prepolymers is that, in the early stages of reaction, polymerization occurs by the normal free radical propagation mechanism of adding monomer to a growing polymer chain. As the population of prepolymer chains with a molecular weight of about 8000 increase in the reaction mixture, they begin to react with each other through pendant allyl groups resulting in a different population of polymers with a significantly higher molecular weight. This creates a multimodal distribution. If this were to continue, crosslinking would eventually occur.

Results and Discussion of Mound Facility Characterization of DAP Molding Compounds

The four batches of DAP prepolymers sent to Mound for evaluation were purposely selected because they represent a wide range of prepolymer types. DAPP $14 / 15$ has a low molecular weight and a unimodal distribution and represents the lower limit of DAP which can be synthesized reasonably. DAPP 39 represents the upper limit of prepolymer that can be prepared before gelation occurs during synthesis. It has the highest molecular weight, broadest molecular weight distribution, and is trimodal. The other two prepolymers, DAPP 11 and DAPP 40, have primarily a bimodal distribution and have properties similar to Dapon 35 and Daiso 35.

The general process for preparing molding compound at Mound was the following:

1. The DAP prepolymer was dissolved in acetone in a small, 8-I sigma blade mixer. 
2. The other components, fiberglass, glass spheres, DAP monomer, peroxide catalyst, hydroquinone, and calcium stearate were added and mixed for $15 \mathrm{~min}$ before evaporation of the acetone under a vacuum.

3. The mixture was given a partial cure, B-staging, on a tworoll mill in which one roller was heated to $92^{\circ} \mathrm{C}$ and the other to $56^{\circ} \mathrm{C}$.

4. The milled sheet was cooled to room temperature, ground to pass through a $1.25 \mathrm{~cm}$ screen, and dried in air for a minimum of $24 \mathrm{~h}$ at room temperature.

5. When required, the material was heated in an oven to provide additional B-staging. The amount of B-staging was adjusted to give about the same degree of cure normally obtained with Dapon 35. This was determined by differential scanning calorimetry.

The processing conditions and characteristics of the molding compounds determined by Mound are provided in Table 2 (w/o equals weight percent). The two Bendix prepolymers most similar in molecular weight properties to Dapon 35 (DAPP 11 and DAPP 40) processed very much like both Dapon 35 and Daiso 35 and were rated excellent in ease of processability.

Problems were observed in processing molding compound made from DAPP 14/15, the low molecular weight (unimodal distribution) prepolymer, and molding compound made from DAPP 39, the highest molecular weight (trimodal distribution) prepolymer. Molding compound made from DAPP $14 / 15$ was very tacky and difficult to mil1. Not even additional B-staging yielded a molding compound with an acceptable Monsanto Rheometer minimum torque value. A second batch of molding compound using DAPP 14/15, in which DAP monomer was eliminated and additional fiberglass and peroxide were incorporated, was slightly improved in ease of processability but still was unacceptable to Mound personnel. Low molecular weight prepolymers such as DAPP $14 / 15$ appear to have too low a viscosity for the processing conditions employed and cannot be B-staged adequately in a reasonable time period.

The molding compound made from DAPP 39 was difficult to dissolve in acetone and, in fact, was not completely soluble in acetone; however, the material milled readily. The fact that DAPP 39 did not completely dissolve suggests it might have contained some 
Table 2. Processability of DAP Prepolymers in DAP Fiberglass Molding Compounds

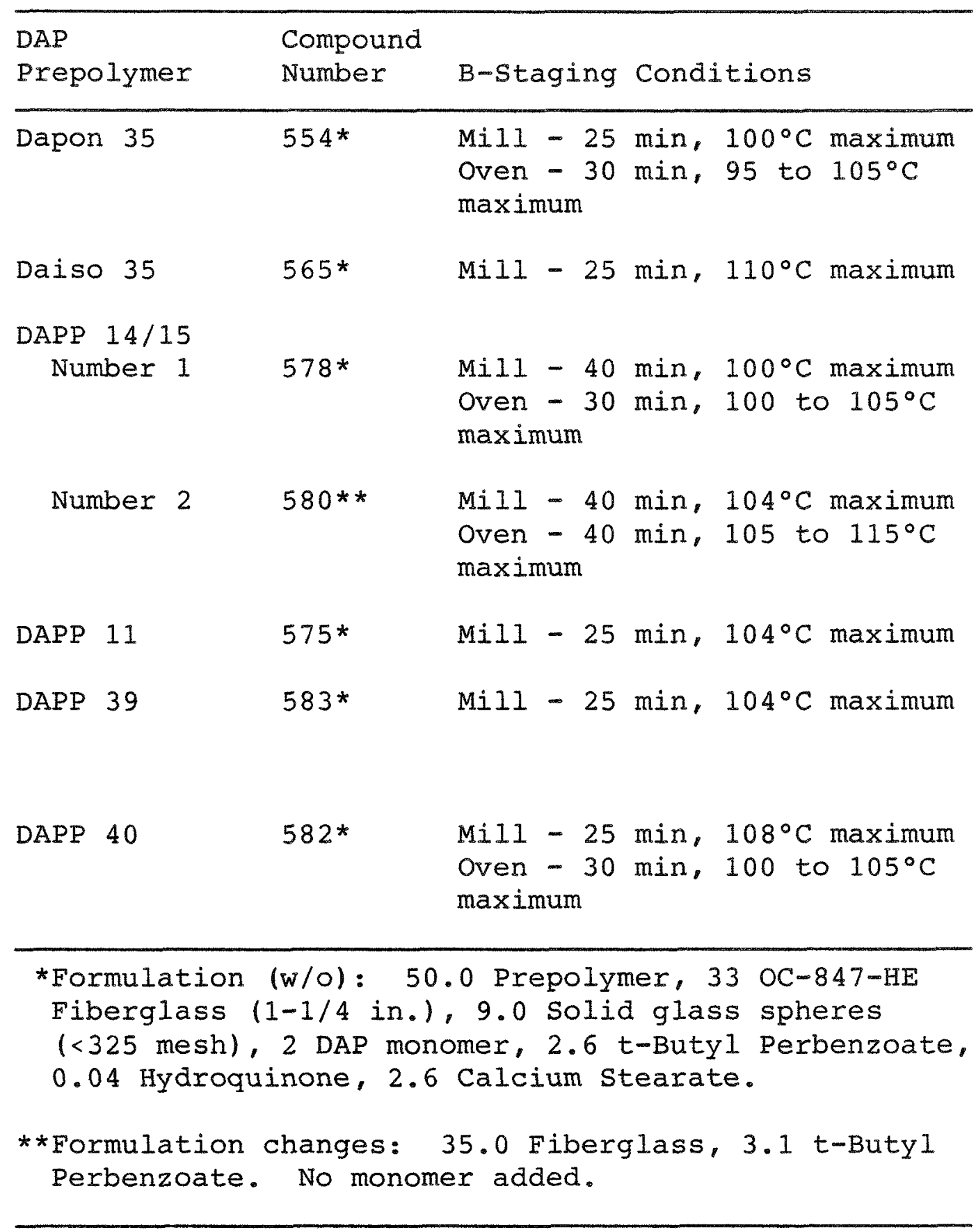


micro-gels of partially crosslinked prepolymer. As discussed earlier, DAPP 39 was at the brink of gross gellation before the reaction was terminated.

Mound tested the molding compounds using the same certification test requirements for molding compounds made from Dapon 35. Several other tests Mound routinely performs on DAPP for information purposes were also made. The analyses performed and results obtained are listed in Tables 3 through 5.

The values of 0.39 and 0.40 percent total chlorine found in DAPP 39 and DAPP 40 are considered to be unacceptably high. Mound requires a level of chlorine less than 0.3 percent. The chlorine in these prepolymers is attributed to the use of carbon tetrachloride as a chain transfer agent. Future development effort should include the evaluation of non-halogen chain transfer agents or decreasing the amount of carbon tetrachloride used. The other two Bendix prepolymers, DAPP $14 / 15$ and DAPP 11, had acceptable levels of chlorine.

As observed in Table 5, molding compound made from Bendix prepolymer DAPP 11 met all the acceptance testing requirements. Compound made from DAPP 39 and DAPP 40 failed only one test, arc resistance; however, in discussions with Mound personnel, these failures are probably caused by problems with the test method at the time of testing and not necessarily the material. Molding compound made from DAPP $14 / 15$ failed both the arc resistance and heat distortion testing even after additional B-staging of the compound. These results combined with the processing difficulties observed with DAPP 14/15, prohibit this type of a prepolymer from being considered as a candidate for use at Mound.

Because only 500 to $600 \mathrm{~g}$ of Bendix prepolymer was available, only a few test specimens of molding compounds for each test performed at Mound could be prepared. In the cases identified in Table 5, only one test specimen was prepared. Normally, many specimens are prepared and tested by Mound for acceptance certification.

Mound personnel were encouraged by the Bendix prepolymers, especially DAPP 11. The same is true with DAPP 40 , assuming the arc resistance test data were a result of the method and not the material, and the problem with chlorine content can be resolved. 
Table 3. Analysis and Methods Used in the Mound Characterization of DAP Molding Compounds

\begin{tabular}{ll}
\hline Analysis & Method \\
\hline Iron & Emission Spectroscopy \\
Barium & Emission Spectroscopy \\
Total Chlorine & \\
$\quad$ (including bromine) & ASTM D-808 \\
Ionic Chlorine & ASTM D-808 \\
Ash & Pyrolysis \\
Volatiles & Mound Procedure, 4 h/105 ${ }^{\circ} \mathrm{C}$ \\
Heat of Reaction $\left(\Delta \mathrm{H}_{\mathrm{r}}\right)$ & Differential Scanning Calorimetry \\
$\Delta \mathrm{H}_{\mathrm{r}}$ Temperature & \\
$\quad$ Maximum & Differential Scanning Calorimetry \\
Minimum Torque & Monsanto Rheometer \\
Tensile Strength & ASTM D-651 \\
Impact Strength & ASTM D-265A \\
Compressive Strength & ASTM D-695 \\
Arc Resistance & ASTM D-495 \\
Heat Distortion Tem- & \\
$\quad$ perature & ASTM D-648 \\
Mesa Spiral Flow & Mound Precedure
\end{tabular}

The results from this endeavor indicate the manufacture of DAP prepolymers in the Bendix Chemical Polymer Facility is feasible. The processes involved and equipment currently being installed are well within the capability required. A new endeavor, "Scale-up Synthesis of Diallyl phthalate Prepolymer," recently has been appropriated to develop the processes required for the manufacture of a maximum of $450 \mathrm{~kg}$ of prepolymer/batch.

\section{ACCOMPLISHMENTS}

Several laboratory methods for the synthesis of diallyl phthalate prepolymers have been evaluated and at least one has yielded prepolymer that has characteristics similar to FMC Corporation's Dapon 35. Prepolymers with various types of molecular weight distributions were prepared and evaluated in molding compounds. Molding compounds made from at least one prepolymer met all the Mound Facility processing and certification criteria. 
Table 4. Mound Chemical Analysis of Diallyl Phthalate Fiberglass Molding Compounds

\begin{tabular}{lllll}
\hline $\begin{array}{l}\text { DAP Prepolymer } \\
\text { In Molding } \\
\text { Compound }\end{array}$ & $\begin{array}{l}\text { Iron } \\
\text { (Percent) }\end{array}$ & $\begin{array}{l}\text { Barium } \\
\text { (Percent) }\end{array}$ & $\begin{array}{l}\text { Total } \\
\text { Halogen } \\
\text { (Percent) }\end{array}$ & $\begin{array}{l}\text { Ionic } \\
\text { Halogen } \\
\text { (Percent) }\end{array}$ \\
\hline Dapon 35 & 0.2 & 0.02 & 0.03 & $<0.001$ \\
Daiso 35 & 0.3 & 0.04 & 0.03 & 0.001 \\
DAPP 14/15 & 0.3 & 0.02 & 0.01 & $<0.0002$ \\
DAPP 11 & 0.3 & 0.05 & 0.005 & 0.001 \\
DAPP 39 & 0.2 & 0.02 & 0.40 & $<0.001$ \\
DAPP 40 & 0.2 & 0.03 & 0.39 & 0.007 \\
\hline
\end{tabular}

Potentially, such prepolymers would also be suitable for the manufacture of molding compounds used at Bendiy. The scale-up of the laboratory procedure to manufacture pilot plant quantities of DAP prepolymer in the Bendix Chemical Polymer Facility is feasible. 
Table 5. Properties of DAP Prepolymers in Shortglass DAP Molding Compounds

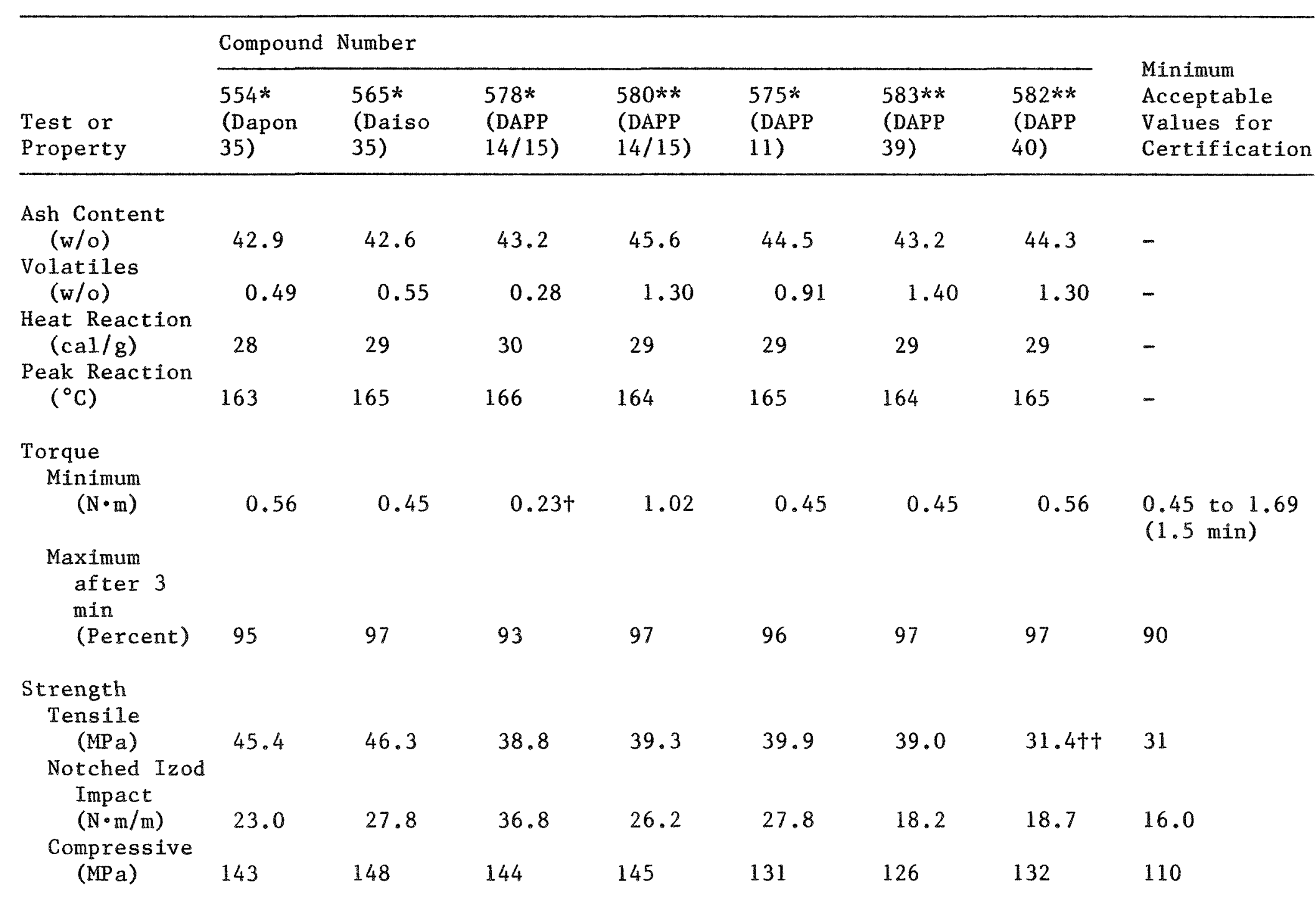


Table 5 Continued. Properties of DAP Prepolymers in Shortglass DAP Molding Compounds

\begin{tabular}{|c|c|c|c|c|c|c|c|c|}
\hline \multirow[b]{2}{*}{$\begin{array}{l}\text { Test or } \\
\text { Property }\end{array}$} & \multicolumn{7}{|c|}{ Compound Number } & \multirow{2}{*}{$\begin{array}{l}\text { Minimum } \\
\text { Acceptable } \\
\text { Values for } \\
\text { Certification }\end{array}$} \\
\hline & $\begin{array}{l}554^{*} \\
\text { (Dapon } \\
35)\end{array}$ & $\begin{array}{l}565 * \\
\text { (Daiso } \\
35)\end{array}$ & $\begin{array}{l}578 * \\
\text { (DAPP } \\
14 / 15 \text { ) }\end{array}$ & $\begin{array}{l}580 * * \\
\text { (DAPP } \\
14 / 15)\end{array}$ & $\begin{array}{l}575 * \\
\text { (DAPP } \\
11)\end{array}$ & $\begin{array}{l}583 * * \\
\text { (DAPP } \\
39)\end{array}$ & $\begin{array}{l}582 * * \\
\text { (DAPP } \\
40)\end{array}$ & \\
\hline $\begin{array}{l}\text { Arc Resis- } \\
\text { tance (s) }\end{array}$ & 122 & 121 & Fails & Fails & 124 & Fails & Fails & 115 \\
\hline $\begin{array}{l}\text { Heat Distor- } \\
\text { tion }\left({ }^{\circ} \mathrm{C}\right)\end{array}$ & 170 & 165 & $147 t$ & $152 t$ & 175 & 173 & 172 & 160 \\
\hline $\begin{array}{l}\text { Mesa Spiral } \\
\text { Flow }(\mathrm{cm})+\dagger\end{array}$ & 28 & 50 & 103 & 29 & 61 & 36 & 23 & - \\
\hline
\end{tabular}

*Molded for 8 min at 135 to $140^{\circ} \mathrm{C}$. $* *$ Molded for $8 \mathrm{~min}$ at $150^{\circ} \mathrm{C}$.

tFailed Test.

t+Measured on one specimen. 


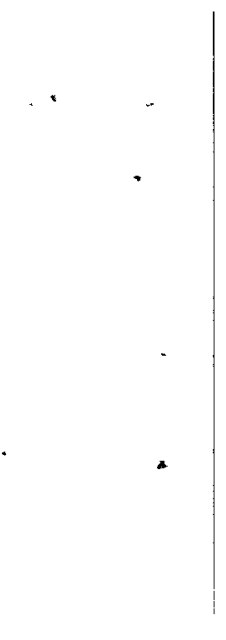


REFERENCES

${ }^{1}$ C. A. Heiberger, United States Patent $3,096,301$, assigned to FMC Corporation, July 2, 1963.

2M. I. Strumik and others, Journal of Applied Polymer Science, Volume 26,1981, p. 3537. 